\title{
Environmental Health Risk and the Use of Biomass Stoves in Sri Lanka
}

\author{
Myles F. Elledge, MPIA, Sumal Nandasena, MBBS, MSc, MD, \\ Michael J. Phillips, BS, and Vanessa E. Thornburg, MA
}

\section{Summary}

This research brief examines environmental health risk and biomass fuel stove use in Sri Lanka. For the majority of Sri Lankan households, biomass fuel is the main resource for cooking. These fuels are a major source of indoor air pollution (IAP). Sri Lanka's population demographic trends show both a large young population and a sizeable aging population, which is unusual in a lower income country. These factors suggest that IAP is a serious health risk for large segments of the population that are likely to be inside the home during biomass stove operation. IAP is a neglected public health issue in Sri Lanka from both the public perspective and the government policy perspective. Further research and analysis are needed to inform public health policy, advocacy, and targeted interventions.

\section{Indoor Air Pollution and Biomass Stoves}

Globally, more than three billion people depend on solid fuels, particularly biomass fuels (wood, dung, crop residues) and coal for cooking, heating, and lighting. The widespread use of biomass stoves that burn these fuels is a leading source of indoor air pollution (IAP). This pollution is not benign. According to the World Health Organization (WHO), ${ }^{1}$ IAP from the use of solid fuels in households in the developing world is responsible for more than 1.6 million premature deaths each year.
Exposure to IAP from solid fuels has been linked to acute and chronic diseases, such as pneumonia, acute respiratory infections, tuberculosis, asthma, cardiovascular disease, cataracts, and adverse perinatal health outcomes (stillbirth, low birth weight). ${ }^{2}$ For example, IAP is a leading cause of pneumonia and other acute lower respiratory infections (ALRI) among children under 5 years of age, and leads to high rates of chronic obstructive pulmonary disease (COPD) in adults. ${ }^{3}$

\section{Indoor Air Pollution and Biomass Stoves}

- More than 3 billion people depend on solid fuels, particularly biomass fuels, for cooking, heating, and lighting

- Exposure to IAP from solid fuels is linked to acute and chronic diseases

- Long-term exposure to IAP may cause cancer and other long-latency diseases

IAP also is suspected to be responsible for a range of cancers from long-term exposures. ${ }^{2}$ The known carcinogenic emissions from combustion of solid fuels suggest that elevated cancer rates will be found among individuals exposed. Diseases with extended latency periods, however, have received far less epidemiologic attention in developing countries than acute diseases. Most commonly in such countries, stove intervention studies have examined only short-term exposure. In particular, IAP in Sri Lanka is a neglected public health issue that has not been well studied. 


\section{The Health Risk of Biomass Stove Use}

Combustion of biomass fuels for cooking produces a range of substances harmful to human health, including particulates, carbon monoxide, nitrogen oxides, sulfur oxides, formaldehyde, and polycyclic organic matter, which includes such carcinogens as benzopyrene. ${ }^{4,5,6}$

- Particulates are extremely hazardous, especially particulate matter less than $2.5 \mu \mathrm{m}$ (micrometers) in diameter and smaller, known as $\mathrm{PM}_{2.5}$. Particulates can penetrate deep into the lungs and cause bronchial irritation, inflammation, and fibrosis. They also can reduce both mucocilliary clearance and macrophage response, which protect the respiratory system from infection. These mechanisms of action can cause wheezing, exacerbate asthma, and lead to respiratory infections.

- Carbon monoxide binds with hemoglobin to produce $\mathrm{COHb}$, which reduces the delivery of oxygen to key organs, including those in developing fetuses. This may result in low birth weight and increased perinatal deaths.

- Acute exposure to nitrogen dioxide increases bronchial reactivity, which can cause wheezing and exacerbation of asthma. Long-term exposure increases susceptibility to bacterial and viral lung infections.

- Acute exposure to sulfur dioxide can cause acute increases in bronchial reactivity, which can lead to wheezing, exacerbation of asthma, COPD, and cardiovascular disease conditions.

- Formaldehyde can cause nasopharyngeal and airway irritation, which can lead to asthma and increased susceptibility to infections.

- Benzopyrene, a carcinogenic substance, is known to cause lung cancer and cancer of the mouth, nasopharynx, and larynx.

- Absorption of toxins in biomass smoke into the lenses of the eyes can cause oxidative changes that can lead to cataracts.

\section{Indoor Air Pollution in Sri Lanka: A Significant Health Risk}

Sri Lanka faces significant mortality and morbidity risk from IAP, and adequate steps have not yet been taken to fully characterize the risk and to inform both citizens and government policy makers. This brief profiles environmental health risk and biomass fuel stove use in Sri Lanka, and draws attention to the lack of comprehensive analytical research and program interventions on the widespread use of biomass fuels by poor households. IAP is not currently identified as a prominent public health issue in Sri Lanka even though large segments of the Sri Lankan population, particularly women and children and its sizable aging population, are often indoors during cooking and consequently most at risk of IAP-related illness.

\section{Summary of IAP Risks, Sri Lanka}

- Sri Lanka faces significant mortality and morbidity risk from IAP

- Biomass fuel stoves are the main source of cooking for $78 \%$ of Sri Lankan households

- IAP health risks disproportionately affect the poor, and especially women, children, and Sri Lanka's sizable elderly population

\section{Biomass Stove Use in Sri Lanka: A Critical Element of IAP}

For the majority of Sri Lankan households, biomass fuel is the main energy resource for cooking, and it is a major source of IAP. Firewood is the predominant biomass fuel, used by more than $78 \%$ of households nationwide, as measured by the Demographic and Health Survey (DHS) in 2000 and 2007). ${ }^{7,8}$ Animal dung and crop residue serve as alternative fuel sources. In $2007,34 \%$ of the population in urban areas, $84 \%$ of the rural population, and $96 \%$ of the estate population used firewood as their primary fuel source. More than $80 \%$ of Sri Lankan households have electricity, but it is only used for lighting due to cost. 8,9

Biomass stove use in Sri Lanka is most common in poor rural areas and on the estates. Generally, people who live in urban areas have more income, have less access to biomass fuel, and use liquid propane or kerosene for cooking. Figure 1 illustrates population density and the percentage of households using firewood. Data are mapped for 18 districts, as socioeconomic data are not available for the conflict-affected North and East districts (shown in gray). 


\section{Figure 1. Population Density and Percentage of Sri Lankan Households Using Firewood, by District-2001}

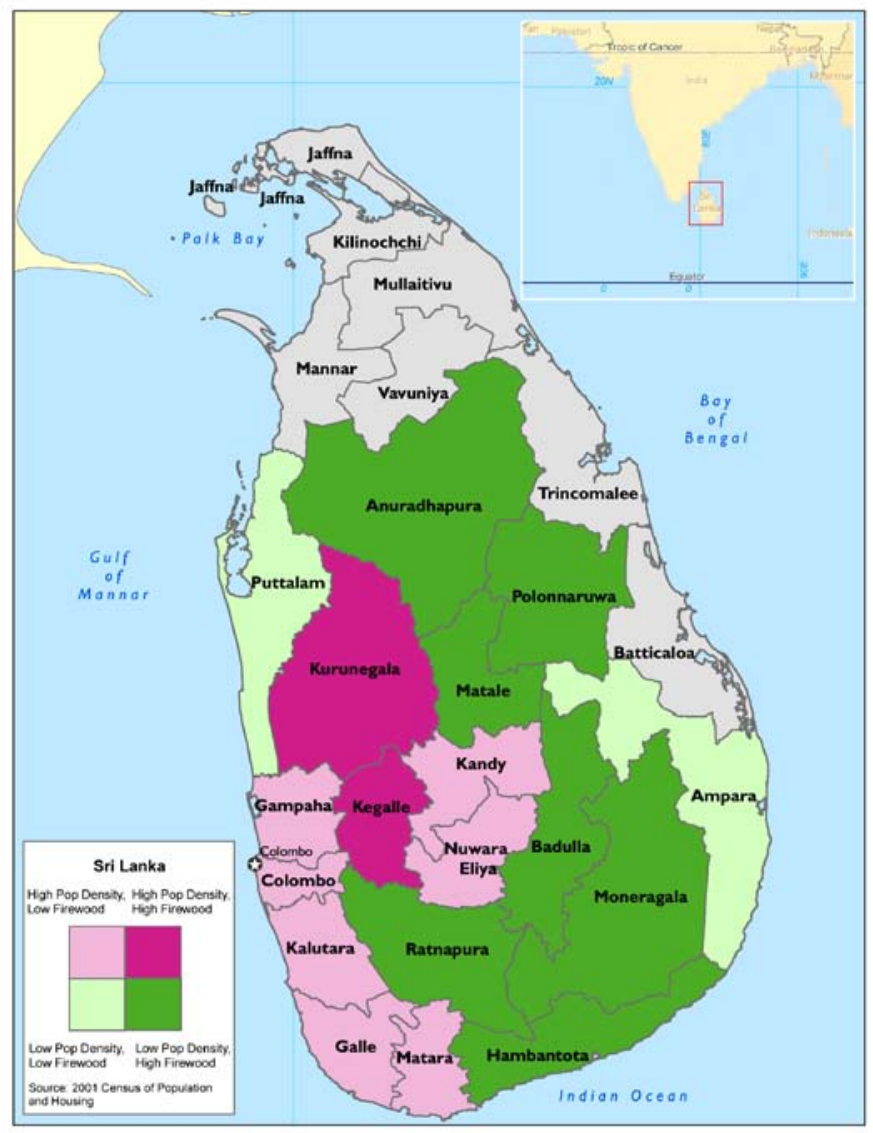

\section{Sri Lanka}

Sri Lanka is an island nation in South Asia with 9 provinces, 25 administrative districts, and a total land area of about 65,000 square kilometers. Among the population of 20 million people, approximately $15 \%$ live in urban areas, $80 \%$ are characterized as rural, and $5 \%$ reside on (rural) "estates," which are categorized separately from other rural areas. They include tea, coconut palm, or other rural and agricultural-based plantations. Sri Lanka is ethnically, linguistically, and religiously diverse, with the majority being Sinhalese and Buddhists. Specifically, the ethnic makeup of Sri Lanka is $75 \%$ Sinhalese, $18 \%$ Tamil, and $7 \%$ Moors; the remainder are Burghers, Malayas, and other minor ethnic groups.
Firewood use is widespread. However, it is used less in the more urban and more developed districts ("high population density" on the map) than in the less developed and rural districts. This pattern is found in many countries with similar socioeconomic conditions and fuels availability. Biomass stove use is most prevalent among rural and poor populations, and both of these conditions present significant barriers to the use of more efficient and safer stove fuels.

The Moneragala District has the highest percentage of biomass fuelwood use (95\%); the largely urban Colombo District has the lowest percentage (33\%). ${ }^{8}$ Generally, the higher the education level, the lower the observed use of firewood. Among women with more than a tenth-grade education, $65 \%$ use biomass fuel; $95 \%$ of the women with only primary schooling or less education use biomass fuel. ${ }^{10} \mathrm{~A}$ higher percentage of Buddhists use biomass stoves than individuals practicing other religions, and a higher percentage of Sinhalese use biomass stoves than other ethnicities. ${ }^{10}$

Most cooking in Sri Lanka is done indoors. Approximately $70 \%$ of the households using biomass fuel cook inside their main household structure; $8 \%$ of the households have a separate building for cooking. ${ }^{7}$ Fewer than $50 \%$ of the households using biomass cooking stoves have a chimney in their house or kitchen. ${ }^{4}$

The majority of cookstoves used are either three-stone (Figure 2) or semi-enclosed types (Figure 3). The thermal efficiency of a typical Sri Lankan three-stone stove is very low, and emissions into poorly vented indoor settings are significant. For example, kitchens in which firewood was used with traditional stoves reported average $\mathrm{PM}_{2.5}$ concentrations of about $1,200 \mu \mathrm{g} / \mathrm{m}^{3}$ (micrograms per cubic meter)..$^{9}$ These high levels are clearly a concern, given that the $\mathrm{WHO}$ recommended guideline for ambient levels of $\mathrm{PM}_{2.5}$ is a 24 -hour mean of $25 \mu \mathrm{g} / \mathrm{m}^{3} .{ }^{11}$ 
Figure 2. Typical household three-stone stove

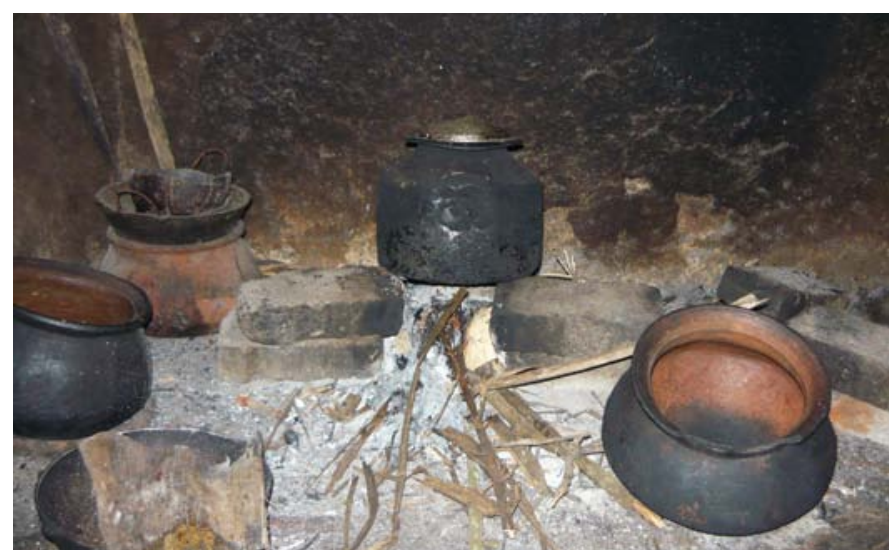

Figure 3. Improved semi-enclosed stove and chimney



\section{Health Impact of IAP and Biomass Stove Use on the Sri Lankan Population}

High concentrations of indoor air pollutants represent a significant health issue for Sri Lankan household occupants. Sri Lanka's population demographic trends show both a large young population and a sizeable aging population, which is unusual in a lower income country. Consequently, IAP is a serious risk for large segments of the population that are likely to be inside the home during stove operation.

Poor and less educated Sri Lankans who live in rural areas are at the greatest risk. Because the costs are prohibitive, the poor are least likely to use cleaner fuels or to have a ventilated kitchen as shown in Figure 3. Women and children, in particular, typically are cooking or present in the home during meal preparation, which means they are more exposed to the airborne particles produced by burning biomass.

Respiratory disease is a leading cause of hospitalization among all age groups in Sri Lanka. In 2002, "diseases of the respiratory system" ranked as the second leading cause of hospitalizations. ${ }^{12}$ Asthma and respiratory disease morbidity also showed an increasing trend. ${ }^{13}$

- Children. According to a 2009 WHO report, 1 respiratory disease accounted for $9 \%$ of all deaths among children under age 5 in Sri Lanka. In 2007, the Sri Lankan government reported that respiratory disease was the fourth leading cause of death in children 1 to 4 years of age. ${ }^{12}$ In addition, WHO reported that respiratory disease was the fifth leading cause of neonatal death. ${ }^{1}$

- Elderly. In 2000, 9.2\% of the Sri Lankan population was older than 60 , which exceeded the average of all regions in the world, except for the most developed countries. ${ }^{14}$ The elderly, particularly women, are likely to be inside the home and exposed to IAP during biomass stove use. Consequently, they are at increased risk for developing cataracts, heart disease, and respiratory diseases. Mortality rates among the elderly have not improved in Sri Lanka, primarily because of increasing mortality in older adults from noncommunicable diseases, particularly ischemic heart disease, stroke, and diabetes.

- Pregnancy and Neonatal Outcomes. Pregnant women and their unborn children in Sri Lanka face additional risks from exposure to biomass fuels and IAP. Sri Lanka, like many developing countries, has a considerable burden of stillbirths and neonatal deaths. According to the 2007 DHS, infant mortality per 1,000 live births was 10 in urban areas, 19 in rural areas, and 29 on the estates. ${ }^{8}$ Respiratory disease ranks fifth among all causes of neonatal death. Exposure to IAP greatly increases the risk of fetal hypoxia, which impairs fetal development. The risk of stillbirths increases with exposure to biomass smoke. Low-birthweight deliveries also are associated with IAP: an estimated $22 \%$ of Sri Lankan infants are born with low birth weight. ${ }^{1}$ Small studies in other Asian countries have suggested a correlation between miscarriage and wood fuel use in the home. 
- Tobacco Use Confounding. Biomass stove use is considered the largest IAP factor in Sri Lanka. In contrast, the prevalence of tobacco use in Sri Lanka is relatively low compared with other Asian countries. Among adults (aged 15 or older), tobacco use rates are $30 \%$ for males, nearly $3 \%$ for females, and $16 \%$ for both sexes combined. Among adolescents (aged 13 to 15$)$, the corresponding rates are $12 \%$ for males, nearly $6 \%$ for females, and $9 \%$ for both sexes combined. ${ }^{1}$ Understanding the levels of exposure to secondhand tobacco smoke is critical in planning biomass stove interventional studies because these levels can confound the point at which the intervention is deemed "successful" and make it more difficult to attribute improved-stove interventions to reductions in ALRI cases.

- Societal Burden. IAP clearly is a significant burden on the public health system in Sri Lanka. WHO estimates the number of deaths attributable to IAP in Sri Lanka in 2009 at 4,300. ${ }^{15}$ Nandasena et al. ${ }^{16}$ identified a limited number of studies that suggested an association between IAP (assessed directly or through proxy measures) and negative health effects. The health care burden associated with IAP includes expenses for medical treatment of the sick and costs attributed to mortality for adults and children. Time absent from work and reduced productivity at work are important factors in considering the impact of IAP. The measurement of disability-adjusted life years (DALYs) - a measure of overall disease burden that combines mortality and morbidity into one measure to capture equivalent years of "healthy" life lost from poor health or disability-is an area to quantify through further research. DALYs could be a driver for public policy and community action to address IAP.

\section{Public Policy and Programming}

IAP has attracted only limited public health attention or programmatic interventions in Sri Lanka. The country has no national action plan for IAP management and no suitable implementation mechanism. Few IAP studies have been conducted to date, as the Ministry of Health has focused on communicable diseases and the Ministry of Environment has focused on outdoor air pollution, particularly vehicular emissions. Moreover, national health, environmental, and energy policies have not fully addressed IAP risks or widespread biomass stove use as

\section{Key Research and Policy Recommendations}

- Applied research on a broader scale to better understand IAP exposure, stove use practices, and health risk is required to develop improved data for public health programming and decision making

- Increased awareness and education about the public health risk of IAP are needed to stimulate policy, technology innovation, and behavior change

- Technology development to design and test culturally appropriate stoves and household ventilation techniques is critical to targeting reductions in IAP exposure

a public priority. The following recommendations are offered for next steps in research, education, and public policy.

\section{IAP Research Focusing on Sri Lanka}

Although IAP studies are in progress, they lack links to national policies and programs. For example, several researchers at the University of Moratuwa, the University of Colombo, and the University of Kalaniya have small IAP research efforts underway. To date, however, few of these studies have been published, and the research has not produced large data sets with actual indoor air quality levels. Consequently, this research has not yet been able to help foster public health advocacy.

Future analytical studies will need to focus on the districts where firewood use is most pervasive among the largest population clusters-the densely populated rural districts of Kurunegala and Kegalle (dark pink in Figure 1) - and the seven rural districts with the highest patterns of firewood use (dark green in Figure 1). These districts are also areas where public health resources might be in high demand to address the risk and impact of IAP.

Research into stove use and differences by religion and ethnicity may be important to understand cooking and lifestyle practices, and to reflect cultural factors accurately when public health advocacy and improvedstove programming are being developed. Experience in other countries has shown that biomass stove research and community-based initiatives that target the introduction of new and improved stoves often fail because they do not adequately account for lifestyle and cultural practices in research and program design. 


\section{Educational Needs}

In Sri Lanka, the public and government perception is that ambient air pollution rather than IAP causes respiratory illness. As a result, policy, standards, and IAP program education and mitigation efforts are very limited. To date, this has resulted in a lack of understanding among both stove users and policy makers of the health risk and consequences of IAP.

Working toward a clear understanding of the adverse health effects of IAP is critical. Making this knowledge part of the public health agenda for Sri Lankans at the national, subnational, community, and household levels is equally crucial.

\section{Interventions}

In the past 10 years, the international donor community has not made IAP and biomass stoves a feature of its health or environmental policy or programs in Sri Lanka. A number of community-based efforts through Sri Lankan nongovernmental organizations (NGOs) have targeted programs on improved cookstove development, with attention to the environmental health risk. Groups such as Practical Action and Integrated Development Association (IDEA) are small, charitable organizations involved in community advocacy for safer cooking practices.

Through IDEA's programming, "Anagi" indoor cookstoves-a type of clay stove (Figure 4) - have been introduced and tested in selected villages. Anagi stoves are now produced commercially through the private sector and are available in selected village markets. To a limited extent, the Anagi stove has replaced the traditional three-stone stove in some communities, largely because of its convenience of use and not necessarily for its effectiveness in addressing IAP. IDEA and Practical Action also have implemented pilot programs on improving kitchen ventilation.

Nevertheless, these programs to foster improved technologies remain small. Consequently, to accurately characterize the degree of improvement and inform interventions for the optimal stove technologies, a comprehensive evaluation of the health and environmental impact of improved stoves is needed.
Figure 4. An Anagi stove is a commercialized model offering convenience features

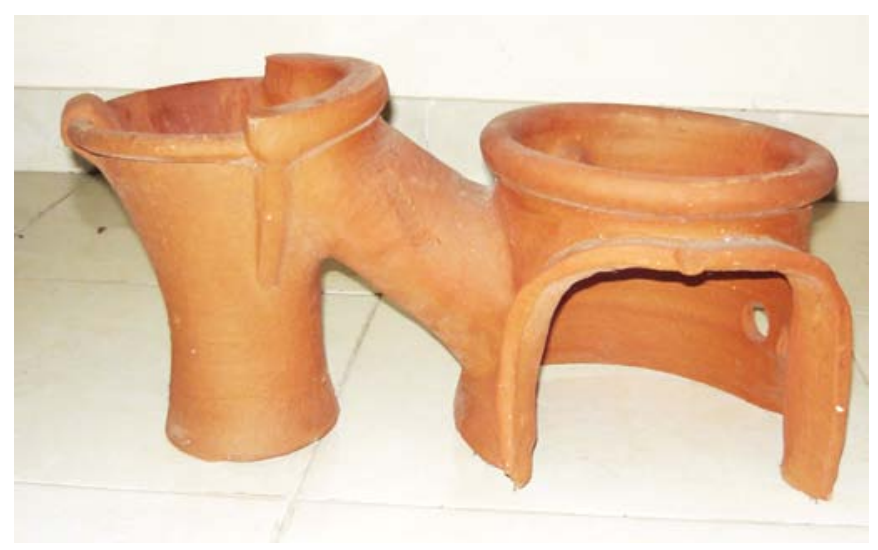

\section{A Framework and Funding for IAP Initiatives}

Addressing IAP effectively will require greater awareness of the widespread use of biomass stoves and the health risk from IAP. Importantly, the very limited IAP advocacy efforts to date have not been conducted under an integrated interventional framework that recognizes that many features-including user education, governmental support, and improved stove availability, among others-must be woven into an effective solution that is sustainable for Sri Lanka. In addition to the funding needed to purchase and apply the interventions, mobilization of public opinion will be required to bring urgency and action through policy development, health education, and community and household interventions.

\section{Conclusion}

Globally, the attributable risk associated with IAP is reasonably well established through comparative riskassessment research. In Sri Lanka, however, few studies have examined indoor air quality and health effects, and the research has largely been done using secondary hospital data, no actual exposure measurements, and very small samples. This is particularly alarming because Sri Lanka's population demographic trends show both a large young population and a sizeable aging population, which suggests that IAP is a serious risk for both of these groups that are often inside homes while biomass stoves are being used. Moreover, the limited research links poverty and biomass use in a way that points to socioeconomic inequalities in terms of health risk. Expanded environmental health research in targeted 
geographic areas is critical to better understand the risk and to promote improved practices.

This brief calls attention to the need for policies to address IAP in Sri Lanka, given the serious health risk for broad segments of the population. It also strongly points to the need for a focused action plan for Sri Lanka to drastically reduce IAP exposure. Standards and monitoring guidelines for IAP also will be important elements. Other priority actions in Sri Lanka should include mounting community-based programs to raise awareness of the environmental health risk of IAP and implementing household interventions to mitigate the risk.

\section{References}

1. World Health Organization. World health statistics [Internet]. Geneva, Switzerland: WHO Press; 2009 [cited 2010 Aug 4]. 149 p. Available from: http://www.who.int/whosis/whostat /EN_WHS09_Full.pdf

2. Smith K. Indoor air pollution in developing countries: recommendations for research. Indoor Air. 2002;12:198-207.

3. Smith-Siversten T, Diaz E, Pope D, Lie R, Diaz A, McCracken J, et al. Effect of reducing indoor air pollution on women's respiratory symptoms and lung function: the RESPIRE Randomized Trial Guatemala. Am J Epidemiol. 2009;170(2):211-20.

4. Bruce N, Perez-Padilla R, Albalak R. The health effects of indoor air pollutant exposure in developing countries [Internet]. Geneva, Switzerland: World Health Organization; 2002 [cited 2010 Aug 4]. 40 p. Available from: http://whqlibdoc.who.int/hq/2002/ WHO_SDE_OEH_02.05.pdf

5. Bruce N, Perez-Padilla R, Albalak R. Indoor air pollution in developing countries: a major environmental and public health challenge. Bull World Health Organ. 2000;78(9):1078-92.

6. Dherani M, Pope D, Mascarenhas M, Smith KR, Weber M, Bruce N. Indoor air pollution from unprocessed solid fuel use and pneumonia risk in children aged under five years: a systematic review and meta-analysis. Bull World Health Organ. 2008;86:390-8.
7. Sri Lanka Demographic and Health Survey 2000 [database on the Internet]. Colombo, Sri Lanka: Department of Census and Statistics, Ministry of Finance and Planning; in collaboration with Ministry of Health, Nutrition, and Welfare. 2002 [cited 2010 Aug 4]. Available from: http://statistics.sltidc.lk/ ddibrowser/?id=1109

8. Sri Lanka Demographic and Health Survey 2006/7 [database on the Internet]. Colombo, Sri Lanka: Department of Census and Statistics in collaboration with Ministry of Health and Nutrition; 2008 May [cited 2010 Aug 4]. 25 p. Available from: http://www.statistics.gov.lk/DHS/DHS\%20Sri\%20 Lanka\%20Preliminary\%20Report.pdf

9. Amerasekera RM. Proven interventions to reduce indoor air pollution due to cooking with biomass. In proceedings of Air That We Breathe, First National Symposium on Air Resource Management in Sri Lanka; 2004 December 2-4; Colombo, Sri Lanka. Colombo: Air Resource Management Center (AirMAC), Ministry of Environment and Natural Resources, 2004. Available from: http://www.cleanairnet.org/caiasia/1412 /article-60275.html

10. Nandasena YLS, Wickremasinghe AR, Sathiyakumar N. Socio-demographic characteristics and principal cooking fuel type in Sri Lanka: comparison of data from two Demographic and Health Surveys. Poster session presented at: 14th Annual Academic Sessions of College of Community Physicians of Sri Lanka; 2009 September 9-12; Colombo, Sri Lanka. Abstract available from: http:// www.ccpsl.lk/files/journals/2009-6.pdf

11. World Health Organization. WHO air quality guidelines for particulate matter, ozone, nitrogen dioxide, global update 2005, summary of risk assessment [Internet]. Geneva, Switzerland: WHO Press; 2006 [cited 2010 Sep 22]. 22 p. Available from: http://www.who.int/phe /health_topics/outdoorair_aqg/en/

12. Annual Health Statistics, Sri Lanka, 2007 [Internet]. Colombo: Medical Statistics Unit, Department of Health Services, Ministry of Healthcare and Nutrition; 2007. 84 p. [cited 2010 Aug 4]. Available from: http://203.94.76.60/AHB2007/Annual\%20 Health\%20Statistics\%202007.html 
13. Annual Health Statistics, Sri Lanka, 2006 [Internet]. Colombo: Medical Statistics Unit, Department of Health Services, Ministry of Healthcare and Nutrition; 2006 [cited 2010 Aug 4]. Available from: http://203.94.76.60/AHB2006/AHS-2006(PDF\%20 FILES)\%20for\%20WEB/Annual\%20Health\%20 Statistics\%202006.htm

14. World Bank. Sri Lanka: Addressing the needs of an aging population [Internet]. Washington, DC: Human Development Unit, South Asia Region, World Bank; 2008 May 28 [cited 2010 Aug 4]. 123 p. Available from: http://siteresources.worldbank.org /INTSRILANKA/Resources /LKAgingFullRep.pdf

15. World Health Organization. Country profiles of Environmental Burden of Disease: Sri Lanka [Internet]. Geneva, Switzerland: World Health Organization; 2009. [cited 2010 Oct 12]. Available from: http://www.who.int/quantifying_ehimpacts /national/countryprofile/srilanka.pdf

16. Nandasena YLS, Wickremasinghe AR, Sathiakumar N. Air pollution and health in Sri Lanka: a review of epidemiologic studies.

BMC Public Health. 2010;10:300.

\section{About the Authors}

Myles F. Elledge, MPIA, is Senior Director of RTI's International Development Group.

Sumal Nandasena, MBBS, MSc, MD, is Lecturer in Public Health at the National Institute of Health Sciences, Ministry of Health, Sri Lanka.

Michael J. Phillips, BS, is a Health Research Analyst in RTI's Social, Statistical, and Environmental Sciences unit.

Vanessa E. Thornburg, MA, is a Survey Manager in RTI's Social, Statistical, and Environmental Sciences unit.
RTI Press Research Briefs and Policy Briefs are scholarly essays on policy, methods, or other topics relevant to RTI areas of research or technical focus. RTI International 3040 Cornwallis Road, PO Box 12194 Research Triangle Park, NC 27709-2194 USA

Tel: $\quad 919.541 .6000 \quad$ Fax: 919.541 .5985

E-mail: rtipress@rti.org Web site: www.rti.org

@2010 Research Triangle Institute. RTI International is a trade name of Research Triangle Institute.

All rights reserved. Please note that this document is copyrighted and credit must be provided to the authors and source of the document when you quote from it. You must not sell the document or make a profit from reproducing it. RTI Press publication RB-0001-1010 doi:10.3768/rtipress.2010.RB.0001.1010 www.rti.org/rtipress 